\title{
Gold Open Access Publishing Must Not Be Allowed to Retard the Progress of Green Open Access Self-Archiving
}

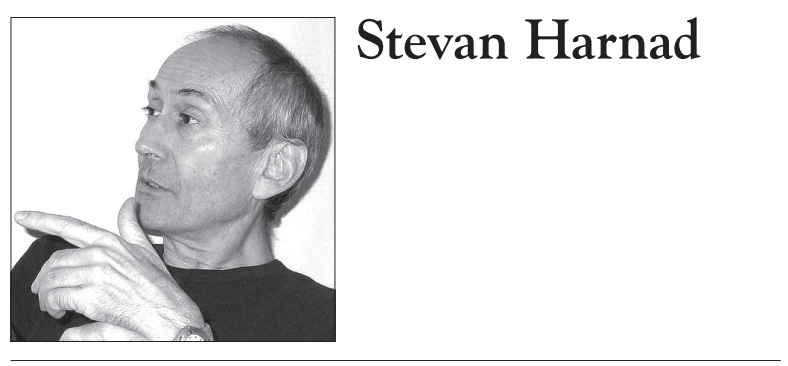

Born in Hungary, Stevan Harnad did his undergraduate work at McGill University and his graduate work at Princeton University. Currently Harnad is Professor in Electronics and Computer Science at University Southampton, UK, and Canada Research Chair in Cognitive Science at Université du Québec à Montréal. He was founder and editor of CUP's Behavioral and Brain Sciences journal, past president of the Society for Philosophy and Psychology, external member of the Hungarian Academy of Sciences, and author and contributor to over 300 publications.

Harnad's research interests are in Open Access Scientometrics, Category Learning, Symbol Grounding and Language Origins. One of the most devoted and outspoken supporters of Open Access to research, Harnad spends a considerable amount of time advocating Open Access to scholarship worldwide.

E-mail: amsciforum@gmail.com

Websites: http://www.ecs.soton.ac.uk/people/harnad http://openaccess.eprints.org

DOI: $10.1163 / 095796511 X 559972$

\section{Introduction}

Universal Open Access (OA) is fully within the reach of the global research community: research institutions and funders need merely mandate (green) OA self-archiving of the final, refereed drafts of all journal articles immediately upon acceptance for publication. The money to pay for gold OA publishing will only become available if universal green $\mathrm{OA}$ eventually makes subscriptions unsustainable. Paying for gold OA pre-emptively today, without first having mandated green $\mathrm{OA}$ not only squanders scarce money, but it delays the attainment of universal $\mathrm{OA}$.

Open Access (OA) means free online access. What made Open Access possible was the advent of the networked online medium: the Internet, and eventually the Web, empowered the authors of digital works to give them away free for all online if they wished.

The term "Open Access" was first coined by the Budapest Open Access Initiative (BOAI), ${ }_{1}$ sponsored by the Open Society Institute $(\mathrm{OSI})^{2}$ in 2001. But the idea of providing free online access - and the provision of free online access - started much earlier than the BOAI and the adoption of the name "OA." The inventors of Unix ${ }^{3}$ and the Internet ${ }^{4}$ - mostly computer scientists - had already been providing $\mathrm{OA}$ to their research papers by self-archiving them in "anonymous FTP archives" since at least the 1970s. With the invention of the $\mathrm{Web}^{6}$ in 1990, websites soon became the preferred way of self-archiving papers. High energy physicists - who had already been systematically sharing their works on paper before the Internet, and then via email when it became possible - began 
self-archiving them in Arxiv, ${ }^{7}$ a centralized physics web archive, in 1991. Many individuals from many other disciplines have since followed the lead of the computer scientists and the physicists.

\section{The "Subversive Proposal" to Self-Archive Refereed Journal Articles}

A "Subversive Proposal" to make all refereed journal articles free for all by self-archiving them online was posted in 1994. The proposal also identified the way to cover the cost of publication if OA self-archiving eventually made subscriptions unsustainable: fees for publishing individual articles instead of subscription fees for accessing them. The first OA journals began appearing in $1989 ;{ }^{9}$ most were either the online versions of subscription journals or they were subsidised online-only journals.

Meanwhile, the 1994 Subversive Proposal to self-archive went largely unheeded: For the following decade, the rate of author self-archiving continued to hover at about $15-20$ percent $^{10}$ of yearly refereed research output. The proportion of articles published in OA journals was even lower. ${ }^{11}$ Providing centralized archives like Arxiv for other disciplines (e.g., CogPrints ${ }^{12}$ for the Cognitive Sciences) likewise failed to increase the rate of $\mathrm{OA}$ self-archiving.

In 1999, the Open Archives Initiative (OAI) ${ }^{13}$ developed a metadata-tagging protocol in order to make all Open Archives "interoperable," which means that depositing locally in any individual archive became equivalent to depositing centrally in one global, seamlessly searchable Open Archive. In 2000, free software (EPrints) ${ }^{14}$ was designed at the University of Southampton (by adapting the CogPrints software to make it OAI-compliant and generic) to make it possible for all universities to create their own OAI-compliant Open Archives (which soon came to be called, instead, "Institutional Repositories" [IRs]). ${ }^{15}$ Many IRs were subsequently created, worldwide - their growth has been monitored by the University of Southampton's Registery of Open Access Repositories (ROAR) ${ }^{16}$ since 2001 - but IRs remained near-empty because $85 \%$ of researchers still were not self-archiving.

In 2001, Steve Lawrence published a paper in Nature reporting that $\mathrm{OA}$ articles in computer science are cited significantly more than non-OA articles. ${ }^{17}$ Many subsequent follow-up studies ${ }^{18}$ confirmed that this "OA impact advantage" was also present in every other scholarly and scientific field tested. But even the OA advantage was not sufficient to induce the $85 \%$ of non-self-archiving authors to do so.

\section{Mandating Self-Archiving}

It had already been proposed since 1998 in the American Scientist Open Access Forum ${ }^{19}$ that universities and research funders should mandate $\mathrm{OA}$ self-archiving (i.e., make it a requirement, as a natural extension of the requirement to publish-orperish). ${ }^{20}$ The School of Electronics and Computer Science at Southampton University (UK) was the first in the world to adopt an OA self-archiving mandate, in 2002. ${ }^{21}$ The first university-wide OA mandate was then adopted by Queensland University of Technology (Australia) ${ }^{22}$ and the first European university-wide mandate by University of Minho (Portugal), ${ }^{23}$ both in 2004.

\section{In 2001, Steve Lawrence published a paper in Nature reporting that OA articles in computer science are cited significantly more than non-OA articles.}

Likewise in 2004, the UK Parliamentary Select Committee on Science and Technology recommended that universities and research funders should mandate OA. ${ }^{24}$ In the same year, the US House Appropriations Committee, too, recommended that NIH should mandate OA. ${ }^{25}$ The UK government failed to act on the Committee's recommendation, yet within a few years all seven of the UK Research Councils nevertheless followed it, each adopting a self-archiving mandate of its own. ${ }^{26}$ The Wellcome Trust became the first research funder to mandate $\mathrm{OA}$ in $2005 .{ }^{27}$ In the same year, NIH adopted an OA request instead of a 
mandate; that policy failed and was upgraded to a mandate in 2007.28

A further incentive to mandate and provide $O A$ was provided by the fact that the outcome of the UK Research Assessment Exercise ${ }^{29}$ - in which peers review and rank the research publications of all departments of all UK universities every six years - turns out to be highly correlated with the citation metrics that $\mathrm{OA}$ has been shown to increase. $^{30}$ The University of Southampton has been strongly promoting the development of OA metrics $^{31}$ to track, evaluate and reward research usage and impact, creating Citebase ${ }^{32}$ as a model for a scientometric engine for research evaluation and navigation and IRStats ${ }^{33}$ for gathering IR usage metrics.

Two international, cross-disciplinary author surveys by Alma Swan in $2005^{34}$ reported the most fundamental strategic and practical finding about why $\mathrm{OA}$ growth had been so slow: although most authors do not self-archive, over 90\% of them indicate that they would self-archive if their funders or institutions mandated it - over $80 \%$ of them indicating they would do so willingly. Outcome studies $^{35}$ from Arthur Sale in Australia have since confirmed that within two years of mandate adoption, compliance rates are indeed over $60 \%$ and well on the road toward 100\%. ROARMAP ${ }^{36}$ shows that the number of mandates is approaching 200 worldwide and now includes Harvard, ${ }^{37}$ MIT, $^{38}$ $\mathrm{UCL}^{39}$ and ETH Zuerich, ${ }^{40}$ as well as the European Research Councillit and the European Commission. ${ }^{42}$

\section{The most frequent misconception about $O A$ is that OA only means Gold OA (publishing).}

\section{Open Access: Green and Gold}

OA self-archiving has come to be called the "green" road to OA (or "Green OA"), to distinguish it from OA journal publishing, which is called the "gold" road to OA ("Gold OA").43 The most frequent misconception about $\mathrm{OA}$ is that $\mathrm{OA}$ only means Gold
OA (publishing). In fact, the fastest and surest road to $\mathrm{OA}$ is the green road of $\mathrm{OA}$ self-archiving, ${ }^{44}$ for two fundamental reasons: (1) providing green $\mathrm{OA}$ is entirely in the hands (and interests) of the providers of the research itself, the global research community, and (2) green OA can be mandated whereas gold $\mathrm{OA}$ is in the hands of the publishing community and cannot be mandated.

Hence green $\mathrm{OA}$ needs to come first, and it needs to be universally mandated, by institutions as well as funders. It has been a great strategic mistake to wait instead for Gold OA.45 If, despite all the benefits, most authors are not providing green OA spontaneously of their own accord, at no cost, and without having to abandon their journal of choice, then they certainly will not provide gold $\mathrm{OA}$, for an additional cost, and having to publish in a gold OA journal instead of their journal of choice. Nor will their institutions have the money to pay their authors' gold OA publishing costs while those funds are still tied up in paying for journal subscriptions. Nor can institutional journal subscriptions be cancelled while the journals' contents are still not otherwise accessible to the institution's users. Moreover, the asking price for gold OA publishing is still much higher than it needs to be, while journals are still producing print and online editions.

If universal green $\mathrm{OA}$ mandates are adopted first, then, if and when the resulting universal green OA makes subscriptions unsustainable as the means of covering publishing costs (because institutions cancel their journal subscriptions), the natural effect will be to induce journal publishers to cut costs, downsize, and convert to gold OA; and the self-same annual windfall savings from the institutional cancellations will be available to pay the institutional authors' costs, per article, of gold OA publishing. Those costs per article will, however, be substantially lower after universal green $\mathrm{OA}$ has made subscriptions unsustainable, because journals will no longer need to provide the print or online edition: all access-provision and archiving will have been offloaded onto the distributed network of green OA IRs. Journals will only provide the service of peer review, ${ }^{46}$ and the institutional savings ${ }^{47}$ will be more than enough to cover its costs.

If, rather than mandating green $\mathrm{OA}$ first and 
waiting for green $\mathrm{OA}$ mandates to propagate globally and to have their natural effects, institutions instead commit some of their scarce available funds to paying pre-emptively for gold OA - and at the current asking price - they will get very little $\mathrm{OA}$ in exchange for their money and they will reinforce gold $\mathrm{OA}$ publishing's current asking price and current modus operandi while failing to grasp the universal (green) OA that is already within their reach. Consortial institutional "membership" commitments (like SCOAP3) 48 - intended to bargain down journal prices in exchange for their converting to gold $\mathrm{OA}$ - are unsustainable, because, unlike subscriptions, they can be cancelled at any time by individual instutions without losing access (because the journals have converted to gold).

Hence the only scaleable, sustainable and certain means of attaining universal $\mathrm{OA}$ is to mandate green $\mathrm{OA}$ first, and to convert to gold $\mathrm{OA}$ only if and when universal green $O A$ makes subscriptions unsustainable. That means institutional cancellations force journals to downsize to providing the peer review service alone while at the same time releasing the institutional subscription cancellation funds to pay for it.

This scenario is independently confirmed by the Houghton report, an economic analysis focussed on publishing costs. Its conclusion is that universal gold OA publishing will eventually save institutions money, but that by far the biggest benefit/cost ratio $^{49}$ can be gained from mandating green $\mathrm{OA}$ today.

\section{“Almost Open-Access"}

Institutional and funder $\mathrm{OA}$ mandates need to be convergent and collaborative ${ }^{50}$ rather than divergent and competitive: institutional deposit followed by central harvesting (not direct central deposit for funder mandates vs. institutional deposit for institutional mandates).

Apart from the two ways of providing $\mathrm{OA}$ (green $\mathrm{OA}$ self-archiving and gold $\mathrm{OA}$ publishing) there are also two forms or degrees of OA: "gratis" $\mathrm{OA}^{51}$ is free online access and "libre" $\mathrm{OA}^{52}$ is free online access plus certain further re-use rights (which may include republication or remixing in derivative works). Both gold OA and libre OA are premature and cannot be mandated; but universal green, gratis
OA will prepare the ground for universal gold OA and increasingly widespread libre OA.

\section{Copyright is not an obstacle to universal OA self-archiving mandates; copyright reform will come as a consequence, not a precondition, of universal green 0 A.}

Copyright is not an obstacle to universal $\mathrm{OA}$ selfarchiving mandates; copyright reform will come as a consequence, not a precondition, of universal green OA. The majority of journals (including almost all the top journals $)^{53}$ already endorse OA self-archiving of the author's refereed final draft, immediately upon acceptance for publication.

For the articles in the minority of journals that do not yet endorse immediate $\mathrm{OA}$ self-archiving, if the author wishes to honor the publisher embargo, the paper can be deposited in the IR immediately upon acceptance anyway, and access to it can be set as Closed Access ${ }^{54}$ instead of OA. IRs have a semi-automated "email eprint request button" 55 that allows any user to request - and the author to provide - an individual copy of a Closed Access deposit for research purposes through just one click each. This is not yet OA; it is "Almost OA," but it will soon hasten the end of OA embargos.

\section{Other Kinds of Content}

OA's primary target is refereed scholarly and scientific journal articles -2.5 million articles per year, published in the planet's 25,000 peer reviewed journals, ${ }^{56}$ across all disciplines, languages and nations - because every one of those articles is, without exception, an author give-away, written solely for research uptake, usage, applications and impact, not for income from sales. Other forms of digital content - books, textbooks, magazine/newspaper articles, music, video, software - are not author give-ways, written for impact rather than income. Here again, the growth of $\mathrm{OA}$ to refereed research 
articles is likely to encourage providing more $\mathrm{OA}$ to these further forms of content too, but it is again a great strategic mistake to treat author give-away content and non-give-away content as if they were all the same sort of thing, under a vague notion of "open access to knowledge."

Another increasingly important form of research content is research data ${ }^{57}$ - but providing immediate $\mathrm{OA}$ to data cannot be mandated because researchers must be allowed a fair period of exclusive time to mine and analyze the data they have gathered. Researchers can also be encouraged - but not required - to provide OA to their pre-refereeing preprints; this must remain a matter of author choice. There is scope, however, for research funders to mandate that as a condition of funding the data on which a peer-reviewed research paper is based must be made OA once the paper has been accepted for publication (with due exceptions for the timing of serial articles all based on mining one data-set).

\section{Open Access Policy Guidance}

The optimal green OA self-archiving mandate is the "Liège model," 58 which designates depositing all papers accepted for publication in the IR as the (sole) mechanism for submitting them for institutional performance review and for national research assessment. Policy guidance for institutions and funders worldwide about designing $\mathrm{OA}$ mandates is being provided by Enabling Open Scholarhhip (EOS), ${ }^{59}$ Open Access Scholarly Information Sourcebook (OASIS), ${ }^{60}$ and SPARC Campus Open Access Policies. ${ }^{61}$

\section{Bibliography}

Gargouri, Y., Hajjem, C., Lariviere, V., Gingras, Y., Brody, T., Carr, L. and Harnad, S. (2010) "Self-Selected or Mandated, Open Access Increases Citation Impact for Higher Quality Research." PLOS ONE 5(10) e13636.

http://dx.plos.org/ambra-doi-resolver/10.1371/journal. pone.0013636.

Harnad, S. (1990) "Scholarly Skywriting and the Prepublication Continuum of Scientific Inquiry," Psychological Science 1: 342-343. http://cogprints.org/1581/.

Harnad, S. (1995) "Universal FTP Archives for Esoteric Science and Scholarship: A Subversive Proposal." In: Ann Okerson \& James O'Donnell (Eds.) Scholarly Journals at the Crossroads; A Subversive Proposal for Electronic Publishing. Washington, DC., Association of Research Libraries, June 1995. http://www.arl.org/sc/subversive/.

Harnad, S. (2001) "The Self-Archiving Initiative." Nature 410: 1024-1025. http://www.nature.com/nature/debates/eaccess/Articles/harnad.html.

Harnad, S., Brody, T., Vallieres, F., Carr, L., Hitchcock, S., Gingras, Y, Oppenheim, C., Stamerjohanns, H., \& Hilf, E. (2004) "The Green and Gold Roads to Open Access." Nature Web Focus. http://www.nature.com/nature/focus/ accessdebate/21.html.

Harnad, S. (2007) "The Green Road to Open Access: A Leveraged Transition." In: Anna Gacs. The Culture of Periodi cals from the Perspective of the Electronic Age. L'Harmattan. 99-106. http://eprints.ecs.soton.ac.uk/13309/.

Harnad, S. (2008) "Waking OA's 'Slumbering Giant': The University's Mandate To Mandate Open Access." New Review of Information Networking 14(1): 51-68.

http://eprints.ecs.soton.ac.uk/17298/.

Harnad, S. (2009) "Open Access Scientometrics and the UK Research Assessment Exercise." Scientometrics 79 (1). http://eprints.ecs.soton.ac.uk/17142/.

Harnad, S. (2009) "The PostGutenberg Open Access Journal.” In: Cope, B. \& Phillips, A (Eds.) The Future of the Academic Journal, Chandos.

http://eprints.ecs.soton.ac.uk/15617/.

Harnad, S. (2010) "No-Fault Peer Review Charges: The Price of Selectivity Need Not Be Access Denied or Delayed." D-Lib Magazine 16 (7/8). http://www.dlib.org/dlib/july10/ harnad/07harnad.html.

Harnad, S. (2010) "The Immediate Practical Implication of the Houghton Report: Provide Green Open Access Now." Prometheus 28: 55-59. http://eprints.ecs.soton.ac.uk/18514/.

Sale, A., Couture, M., Rodrigues, E., Carr, L. and Harnad, S. (2010) "Open Access Mandates and the 'Fair Dealing' Button." In: Dynamic Fair Dealing: Creating Canadian Culture Online (Rosemary J. Coombe \& Darren Wershler, Eds).

http://eprints.ecs.soton.ac.uk/18511/. 


\section{Endnotes}

1 Budapest Open Access Initiative. http://www.soros.org/openaccess/read.shtml.

2 Open Society Institute. http://www.soros.org/.

3 Unix - History and Timeline. http://www.unix.org/what_is_unix/history_timeline.html.

4 Internet Society - A Brief History of the Internet. http://www.isoc.org/internet/history/brief.shtml.

5 A Short History of the Internet. http://bugclub.org/beginners/history/InternetHistory. html.

6 "A Little History of the World Wide Web," The World Wide Web Consortium (W3C). http://www.w3.org/History.html.

7 http://arxiv.org/.

8 "I. Overture: The Subversive Proposal" in Scholarly Journals at the Crossroads: A Subversive Proposal for Electronic Publishing, (1995), Association of Research Libraries. http://www.arl.org/sc/subversive/i-overture-the-subversiveproposal.shtml.

9 Timeline of the Open Access Movement. http://www.earlham.edu/ peters/fos/timeline.htm.

10 Björk, B.-C., Welling, P., Laakso, M., Majlender, P., Hedlund, T., et al. (2010) "Open Access to the Scientific Journal Literature: Situation 2009." PLoS ONE 5(6): e11273. doi:10.1371/journal.pone.0011273.

http://www.plosone.org/article/ info\%3Adoi\%2F10.1371\%2Fjournal.pone.0011273.

11 Gargouri, Y. and Harnad, S., "Mandated and Unmandated Open Access: Comparing Green and Gold."

http://openaccess.eprints.org/index.php?/archives/760guid.html.

12 http://cogprints.org/.

13 http://www.openarchives.org/.

14 http://www.eprints.org/openaccess/.

15 http://en.wikipedia.org/wiki/Institutional_repository.

16 Registry of Open Access Repositories. http://roar.eprints.org/.

17 Lawrence, S., "Free online availability substantially increases a paper's impact," Nature Web Debates.

http://www.nature.com/nature/debates/e-access/Articles/ lawrence.html.

18 "The effect of open access and downloads ('hits') on citation impact: a bibliography of studies." http://opcit.eprints.org/oacitation-biblio.html.
19 Archives of the American Scientist Open Access Forum listserver.

http://amsci-forum.amsci.org/archives/American-Scientist-Open-Access-Forum.html.

20 http://istserver.sigmaxi.org/sc/ wa.exe? $A 2=$ ind $98 \& \&=$ american-scientist-open-accessforum\& $F=1 \& P=1169$.

http://listserver.sigmaxi.org/sc/

wa.exe? $\mathrm{A} 2=\mathrm{ind} 00 \& \mathrm{~L}=$ american-scientist-open-accessforum\& $F=1 \& P=31965$.

21 OA Self-Archiving Policy: University of Southampton: School of Electronics and Computer Science. http://www.eprints.org/openaccess/policysignup/fullinfo. php?inst=University $\% 20$ of $\% 20$ Southampton $\% 3 \mathrm{~A} \% 20$ School\%20of\%20Electronics\%20and\%20Computer\%20 Science.

22 OA Self-Archiving Policy: Queensland University of Technology.

http://www.eprints.org/openaccess/policysignup/fullinfo. php?inst=Queensland\%20University\%20of\%20Technology.

23 OA Self-Archiving Policy: Universidade do Minho. http://www.eprints.org/openaccess/policysignup/fullinfo. php?inst=Universidade\%20do\%20Minho.

24 Recommendations for UK open-access provision policy to UK Government Science and Technology Committee. http://users.ecs.soton.ac.uk/harnad/Temp/UKSTC.htm.

25 Committee Reports - 108th Congress (2003-2004). House Report 108-636.

http://thomas.loc.gov/cgi-bin/cpquery/?\&db_id=cp108\& $\&$ _

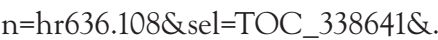

26 http://www.rcuk.ac.uk/Publications/policy/Pages/ResearchOutputs.aspx.

27 OA Self-Archiving Policy: Wellcome Trust. http://www.eprints.org/openaccess/policysignup/fullinfo. php?inst=Wellcome\%20Trust.

Position statement in support of open and unrestricted access to published research.

http://www.wellcome.ac.uk/About-us/Policy/Spotlightissues/Open-access/Policy/index.htm.

28 OA Self-Archiving Policy: National Institutes of Health (NIH).

http://www.eprints.org/openaccess/policysignup/fullinfo. php?inst $=$ National $\% 20$ Institutes $\% 20$ of $\% 20$ Health $\% 20$ $\% 28 \mathrm{NIH} \% 29$. 
29 Mandated online RAE CVs linked to university eprint archives: Enhaning UK research impact and assessment. http://www.ariadne.ac.uk/issue35/harnad/.

30 Harnad, S., Carr, L. and Gingras, Y. (2008) "Maximizing research progress through Open Acces mandates and metrics." Liinc em Revista, v.4, n.2, setembro 2008, Rio de Janeiro, p. 269-273.

http://revista.ibict.br/liinc/index.php/liinc/article/viewFile/282/182.

31 Harnad, S., Carr, L., Brody, T. and Oppenheim, C. (2003) "Mandated online RAE CVs linked to university eprint archives: Enhancing UK research impact and assessment", Ariadne Issue 35.

http://www.ariadne.ac.uk/issue35/harnad/intro.htm.

32 http://www.citebase.org/.

33 http://wiki.eprints.org/w/IRStats.

34 Swan, A. (2005) Open access self-archiving: An Introduction. Technical Report , JISC, HEFCE.

http://eprints.ecs.soton.ac.uk/11006/.

35 Sale, A.H.J. (2006) "Comparison of IR content policies in Australia," First Monday, 11 (4).

http://eprints.utas.edu.au/264/.

36 ROARMAP (Registry of Open Access Repository Material Archiving Policies) as recommended by the Berlin Declaration. http://www.eprints.org/openaccess/policysignup/.

37 OA Self-Archiving Policy: Harvard University: Faculty of Arts and Sciences.

http://www.eprints.org/openaccess/policysignup/fullinfo. php?inst $=$ Harvard $\% 20$ University $\% 3$ A $\% 20$ Faculty $\% 20$ of $\% 20$ Arts $\% 20$ and $\% 20$ Sciences.

38 OA Self-Archiving Policy: Massachussetts Institute of Technology (MIT).

http://www.eprints.org/openaccess/policysignup/fullinfo. php?inst=Massachussetts\%20Institute\%20of\%20Technology\%20\%28MIT\%29.

39 OA Self-Archiving Policy: University College London (UCL). http://www.eprints.org/openaccess/policysignup/ fullinfo.php?inst=University $\% 20$ College $\% 20$ London $\% 20$ $\% 28 U C L \% 29$.

40 OA Self-Archiving Policy: ETH Zürich. http://www.eprints.org/openaccess/policysignup/fullinfo. php?inst=ETH $\% 20 Z \%$ C3\%BCrich.

41 OA Self-Archiving Policy: European Research Council (ERC). http://www.eprints.org/openaccess/policysignup/ fullinfo.php?inst=European\%20Research\%20Council\%20 \%28ERC\%29.
42 OA Self-Archiving Policy: European Commission - 2 (EC). http://www.eprints.org/openaccess/policysignup/fullinfo.php?inst=European\%20Commission\%20-\%202\%20 $\% 28 \mathrm{EC} \% 29$.

43 "The green and the gold roads to Open Access." Nature Web Focus. http://www.nature.com/nature/focus/accessdebate/21.html.

44 Harnad, S. (2007) "The Green Road to Open Access: A Leveraged Transition." In: The Culture of Periodicals from the Perspective of the Electronic Age, pp. 99-105, L'Harmattan. http://eprints.ecs.soton.ac.uk/15753/.

45 Waiting for Gold, Self Archiving FAQ for the Budapest Open Access Initiative (BOAI). http://www.eprints.org/openaccess/self-faq/\#31.Waiting.

46 Harnad, S. (2010) "No Fault Peer Review Charges: The Price of Selectivity Need Not Be Access Denied or Delayed," D-Lib Magazine, Volume 16, Number 7/8. http://www.dlib.org/dlib/july10/harnad/07harnad.html.

47 Harnad, S. (2008) "The Postgutenberg Open Access Journal." In: The Future of the Academic Journal, Chandos, 2009. http://eprints.ecs.soton.ac.uk/15617/.

48 Sponsoring Consortium for Open Access Publishing in Particle Physics (SCOAP3). http://scoap3.org/.

49 Harnad, S. (2010) The Immediate Practical Implication of the Houghton Report: Provide Green Open Access Now. Prometheus, 28 (1). pp. 55-59.

http://eprints.ecs.soton.ac.uk/18514/.

50 Harnad, S., "How to Integrate University and Funder Open Access Mandates," Open Access Archivangelism. http://openaccess.eprints.org/index.php?/archives/369. guid.html.

51 Suber, P., "Open Access: 'Gratis' and 'Libre'," Open Access Archivangelism.

http://openaccess.eprints.org/index.php?/archives/442guid.html.

52 Suber, P., "Green/gold OA and gratis/libre OA," Open Access News. http://www.earlham.edu/ peters/fos/2008/08/ greengold-oa-and-gratislibre-oa.html.

53 Journal Policies - Summary Statistics So Far. http://romeo.eprints.org/stats.php.

54 "The Immediate-Deposit/Optional-Access (ID/OA) Mandate: Rationale and Model," Open Access Archivangelism. http://openaccess.eprints.org/index.php?/archives/71-guid. html. 
55 Sale, A., Couture, M., Rodrigues, E., Carr, L. and Harnad, S. (2010) "Open Access Mandates and the 'Fair Dealing' Button." In: Dynamic Fair Dealing: Creating Canadian Culture Online (Rosemary J. Coombe EJ Darren Wershler, Eds.). http://eprints.ecs.soton.ac.uk/18511/.

56 http://www.ulrichsweb.com/ulrichsweb/.

57 Harnad, S., "Shared Access and Reuse of Publicly Funded Scientific Data," Open Access Archivangelism.

http://openaccess.eprints.org/index.php?/archives/779-

Shared-Access-and-Reuse-of-Publicly-Funded-ScientificData.html.

58 OA Self-Archiving Policy: Université de Liège.

http://www.eprints.org/openaccess/policysignup/fullinfo. php?inst=Universit\%C3\%A9\%20de\%20Li\%C3\%A8ge.
59 Open Access Policies for Universities and Research Institutions.

http://www.openscholarship.org/jcms/c_6226/openaccess-policies-for-universities-and-research-institutions?hlText=policie.

60 Open Access Scholalry Information Sourcebook. Practical Steps for Implementing Open Access.

http://www.openoasis.org/index.php?option=com_ content\&view=article $\&$ id $=148$ :the-optimal-open-accesspolicy-for-institutions\& $\&$ atid=81:articles $\&$ Itemid $=340$.

61 http://www.arl.org/sparc/advocacy/campus/. 